\section{CAMPAIGN LAUNCHED TO HELP ABUSED YOUNG PEOPLE ACCESS SUPPORT}

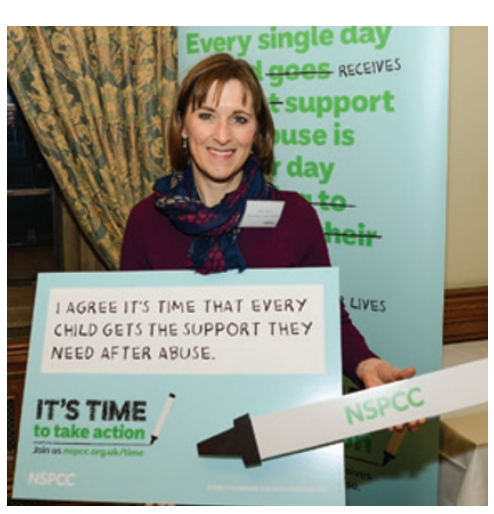

The British Society of Paediatric Dentistry (BSPD) has announced that it supports a campaign launched by the National Society for the Prevention of Cruelty to Children (NSPCC) calling for better mental health support for abused and neglected children and young people. The aim of the 'It's Time' campaign is to help abused or neglected young people access the support they need to recover from the trauma they have experienced. Minister of State for

Community and Social Care, Alistair Burt MP, launched the campaign at the Houses of Parliament on 10 February 2016.

Alistair introduced an NSPCC young ambassador who told guests at the launch why the campaign was so important. He spoke of young people who resorted to self-harm or threats of suicide before they could get help.

Jenny Harris, a specialist paediatric dentist who has done so much to raise awareness of child protection issues among the dental profession (pictured), said: 'This is the most compelling campaign I remember. It seems we have come so far - to get better at recognising signs of abuse and neglect and refer children for help - yet it is scandalous to hear that those same children can't get the support they then need to rebuild their lives.'

To find out how to support the campaign, go to: https://www.nspcc.org. uk/fighting-for-childhood/campaigns/its-time/.

\section{TONY CHIVERS}

Tony, whose obituary is published in this issue (page 374) deserves special mention for his exceptional work for the Benevolent Fund and the Dentists Health Support Programme and Trust. We featured Tony in late 2011 when he was, at age 91, rowing 100 miles in 30 days on a rowing machine to raise money for these two worthy causes.

During his earlier career Tony became aware that the Benevolent Fund had no provision to help those who volunteered for service within the Fund's activities but who subsequently had financial difficulties through their own ill health. He set up a trust fund to help these individuals and managed to attract monies from various sources including the Ministry of Health. This led to the Sick Dentist Scheme and Trust (now known as the Dentists Health Support Programme and Trust) which he founded and of which he became the first chairman. He was made a lifetime trustee by his fellow trustees and attended all meetings of the Trust up to and including the AGM in December 2014. Additionally Tony was a member of the Committee of Management of the Benevolent Fund from 1969 until 1992, being its chairman from 1985 to 1992. He was awarded an MBE for his services to dentistry in 1996. Quite apart from all this, Tony succeeded in his ambitious rowing marathon in 2011 raising over $£ 2,500$. The profession has lost a great friend and tireless supporter. 